\title{
O SURGIMENTO DE HOSPITAIS PSIQUIÁTRICOS NO CEARÁ E AS POLITICAS DE SAÚDE NO BRASIL
}

\author{
Maria Nazaré de Oliveira Fraga * \\ Natália Braga Silva**
}

\begin{abstract}
RESUMO: O presente trabalho enfoca a correlação entre a cronologia de criação dos hospitais psiquiátricos do Ceará com as políticas de saúde no Brasil. A metodologia compôs-se pela realização de visitas ou envio de correspondência às instituições, consultas aos maiores jornais em circulação no Ceará e de estudo bibliográfico sobre as políticas de saúde e saúde mental. O surgimento dos hospitais psiquiátricos foi analisado partindo da delimitação prévia de quatro fases de desenvolvimento da assistência psiquiátrica no País, de acordo com as transformações ocorridas, desde o descobrimento até os nossos dias. A análise evidenciou que o surgimento dos referidos hospitais guarda relação com aquelas fases e que as políticas de saúde vigentes em cada época tiveram forte determinação no rítmo de criação dos mesmos.
\end{abstract}

ABA TRACT: The present paper emphasizes the relationship between the Chronology of psychiatric hospital creation and health policy. The methodology was done by visiting or sending mail to institutions, collecting data from newspapers of Ceará and doing a bibliography study about health policy and mental health. Indeed, the creation of psychiatric hospitals was analysed from previous four phases of development of the psychiatric assistance in the country, according to the changes sisnce the begining to up to date. The analysis revealed that a creation of psychiatric hospitals keep close relationship with those phases and that health policy from each period of time had strong influence on them.

UNITERMOS: Hospitais Psiquiátricos - Política de Saúde.

\section{INTRODUÇÃO}

O presente trabalho surgiu como desdobramento de pesquisa realizada anteriormente cujos resultados já estão publicados(3). Naquela investigação, entre outros dados, foram levantados os anos de criação dos hospitais psiquiátricos do Ceará cuja compilação evidenciou longo período (quase quatro séculos) em que só ao final surgiu um hospital, seguido de outro (mais de sete décadas) em que surgiram três hospitais. No período seguinte, no correr de quatro anos, seis hospitais foram criados e por fim chega-se à fase atual, em que arrefeceu a tendência de criação dos mesmos. Essa tendência irregular chamou-nos a atenção e nos remeteu à iniciativa de associá-la às políticas de saúde e de saúde mental no Brasil, ao longo dos anos, tendo como objetivo explicitar as relações aí existentes.

$\mathrm{O}$ presente estudo também insere-se no esforço de alguns autores cearenses que vêm explicitando as características da prática psiquiátrica na região, bem como sua história e seus determinantes $(2,3,4,5,6)$

\section{METODOLOGIA}

A pesquisa amparou-se em metodologia iniciada com uma primeira compilação de dados obtidos com a realização de visitas ou com o envio de correspondência a todos os hospitais psiquiátricos da região,

\footnotetext{
* Doutora em Enfermagem. Professora Adjunta do Curso de Graduação e do Curso de Mestrado em Enfermagem da Universidade Federal do Ceará.

** Aluna do Curso de Graduação em Enfermagem da Universidade Federal do Ceará. Bolsista de Iniciação Cientifica.
} 
onde através de formulário, foram coletadas, além de outras informações, as datas de criação dos referidos hospitais. Essa coleta abrangeu o total de 12 instituições, a maioria delas localizadas em Fortaleza, e foi concluída em 1991. As datas foram posteriormente colocadas em ordem cronológica para, em seguida, serem correlacionadas com as políticas de saúde vigentes no país em cada época. Também foram consultados os maiores jomais em circulação no Ceará* visando colher informaçס̃es sobre a situação recente da assistência psiquiátrica, as transformaçðes sofridas, as discussð̃es ocorridas em congressos e encontros psiquiátricos locais. A consulta à bibliografia sobre as políticas para o setor saúde e saúde mental é que possibilitou a análise consubstanciada na correlação entre estas e o ritmo de surgimento dos hospitais psiquiátricos.

A pesquisa apoia-se no enfoque histórico-estrutural, utilizando aspectos da história como elementos elucidativos da realidade estudada.

\section{CRIAÇÃO DOS HOSPITAIS PSIQUIÁTRICOS DO CEARÁ E SUA CORRELAÇÃO COM AS POLITICAS DE SAÚDE DO BRASIL}

Este tópico do trabalho visa estabelecer a relação entre a criação dos hospitais psiquiátricos do Ceará e as políticas, de saúde e de saúde mental no País. Entende-se que as referidas políticas, associadas a outros fatores, tiveram forte determinação no ritmo de surgimento dos referidos hospitais e mesmo na predominância do número de instituições privadas, em detrimento da instituições públicas. Por outro lado, oportunamente, será procedida uma análise dos dados e dos tipos de instituições, considerando as características político-econômicas do Ceará.

Antes de apresentar e analisar a cronologia de criação dos hospitais do Ceará admite-se que a assistência psiquiátrica no Brasil, tendo em vista as mudanças políticas que se processaram desde seu descobrimento até os nossos dias, pode ser dividida em fases. Na delimitação de tais fases escolhemos como parâmetro orientador a tendência da assistência psiquiátrica que parece ter caracterizado cada uma delas. Para atender aos objetivos desse trabalho foi adotada a seguinte periodização:

*

O Povo, Diário do Nordeste, Tribuna do Ceará.

\section{Primeiro Período (de 1500 a 1889 - Colónia e Império)}

Durante a maior parte desse período, nåo havia no Brasil uma política oficial de assistência aos lou$\cos$. No início, de alguma forma, eles estavam inseridos na comunidade e na familia, e posteriormente, perambulavam pelas nuas, eram aprisionados em cadeias ou nos porões da Santas Casas. Na última década desse periodo, com o incremento da urbanização em alguns centros do país, e com alguns protestos pelo modo desumano como eram tratados os doentes mentais, iniciou-se a institucionalização da psiquiatria, cujo marco inicial é a criação do Hospício de Pedro II na cidade do Rio de Janeiro. A exemplo do Rio de Janeiro, seguiram-se construções em vários outros estados: São Paulo, Pemambuco, Bahia, Pará, Ceará, entre outros ${ }^{(9)}$. Exigência do processo de urbanização e como parte das medidas de disciplinamento da ordem social e de saneamento das cidades, os hospícios foram sempre construídos fora dos perímetros urbanos.

\section{Segundo Período (de 1889 a 1966)}

Esse período também, de início, ñ̃o conta com uma política oficial ampla do Estado para o setor saúde. $O$ que havia de seguro social era uma organização sob a forma de caixas que abrangia pequena parcela dos assalariados. Em 1953 inicia-se um processo de organização por categorias de empresas e vão sendo criados os Institutos de Aposentadorias e Pensões de Bancários (IAPB), de Industriánios (IAPI), de Comerciários (IAPC), entre outros. À época, o Ministério do Trabalho cria o conselho superior de Previdência Social e o Departamento de Previdência Social para, respectivamente, tratar com questores de contribuições e de supervisão(1). Como o Estado não agia sobre as questões sociais e de saúde, os problemas eram contomados pelos próprios trabalhadores, através das caixas de aposentadoria e pensão, ou recorrendo às instituiçð̃es de caridade ${ }^{(7)}$.

\section{Terceiro Período (de 1966 a 1974)}

O sistema de Institutos de Aposentadorias e Pensões desaparece em 1966, com a criação do Instituto Nacional de Previdência Social, que traz no seu bojo a tentativa do Estado de igualar a assistência prestada 
QUADRO I - Cronologia de Criação dos Hospitais Psiquiátricos do Ceará

\begin{tabular}{|c|c|c|c|}
\hline & ANO DE CRIACCAO & INSTITUIÇס̋ES & CATEGORIA \\
\hline $1^{0}$ Período & 1886 & Instituiçåo VII & Filantropica \\
\hline $2^{\circ}$ Perlodo & $\begin{array}{l}1935 \\
1949 \\
1963 \\
\end{array}$ & $\begin{array}{l}\text { Instituiçăo VI } \\
\text { Instituiçăo V } \\
\text { Instituiçăo I }\end{array}$ & $\begin{array}{l}\text { Privada } \\
\text { Filantrópica } \\
\text { Pública }\end{array}$ \\
\hline $3^{\circ}$ Periodo & $\begin{array}{l}1967 \\
1967 \\
1968 \\
1969 \\
1969 \\
1970 \\
\end{array}$ & $\begin{array}{l}\text { Instituiçă III } \\
\text { Instituiçă XII } \\
\text { Instituiçă IV } \\
\text { Instituiçă II } \\
\text { Instituiçăo XI } \\
\text { Instituiçăo IX }\end{array}$ & $\begin{array}{l}\text { Privada } \\
\text { Privada } \\
\text { Filantrópica } \\
\text { Privada } \\
\text { Pública } \\
\text { Privada } \\
\end{array}$ \\
\hline $4^{0}$ Período & $\begin{array}{l}1974 \\
1978 \\
\end{array}$ & $\begin{array}{l}\text { Instituiçăo VIII } \\
\text { Instituiçăo X }\end{array}$ & $\begin{array}{l}\text { Privada } \\
\text { Privada } \\
\end{array}$ \\
\hline
\end{tabular}

anteriormente nos diferentes institutos, e de responder a reinvidicações da sociedade, pela extensão dos direitos sociais. Este período, no campo da psiquiatria, caracteriza-se pela contratação, por parte do Estado, de leitos em hospitais particulares com recursos descontados compulsoriamente dos salários de todos os trabalhadores. A rede ambulatorial pública, incipiente, funcionou como malha de captação de pacientes para os hospitais privados. Considera-se que nesse período a psiquiatria foi um setor com relativa prioridade no conjunto da assistência à saúde, pelo montante significativo de verbas que a esse setor foi dispensado.

\section{Quarto Periodo (de 1974 em diante)}

O ano de 1974 inicia um período diferente do anterior, no qual havia sido dada relativa prioridade à psiquiatria. O que seria o milagre econômico brasileiro, na verdade, levou à deterioração das condições de vida das classes populares, ao comprometimento de suas condições de saúde e à demanda de cobertura maior por parte dos serviços de saúde. Com o crescimento da demanda, instala-se a crise da Previdência Social e a necessidade do Estado de racionalizar recursos. Isso se reflete na psiquiatria, com a redução dos gastos destinados ao setor, traduzidos pela tentativa de implantação da rede ambulatorial, pelas supervisões e auditorias aos hospitais visando diminuir o tempo de permanência dos pacientes internados, e pela redução do índice de encaminhamentos de pacientes aos hospitais psiquiátricos ${ }^{(8)}$. Diminui o ritmo de criação de hospitais psiquiátricos novos.

Tomando por base a periodização da assistência psiquiátrica no Brasil, em sua relação com a existência ou não de políticas oficiais para esse setor específico, vejamos de que modo surgiram e organizaramse os hospitais psiquiátricos do Ceará. No Quadro I, estão agrupados os referidos hospitais, contendo além do ano de criação de cada um, a categoria a que pertencem (públicos, privados, filantrópicos).

Numa primeira observação do Quadro I pode-se constatar que em 1991, ano em que se concluiu a coleta de dados desta pesquisa, o Estado do Ceará contava com doze hospitais psiquiátricos, sendo sete privados, três filantrópicos e dois públicos.

Passando à análise da cronologia de criação desses hospitais, constata-se que em todo o primeiro período, que vai do descobrimento do Brasil até a Proclamação da República, o Ceará contou apenas com um hospital psiquiátrico, que foi fundado em 1886. Vale lembrar que nesse período, em outras regiões, o Estado assumiu a criação de vários asilos, enquanto que no Ceará a construção do Asilo de Alienados São Vicente de Paulo ocorreu também, e principalmente, pela ação de grupos filantrópicos. $\mathrm{O}$ fato de num período de quase quatrocentos anos o Ceará ter contado com apenas um hospital psiquiátrico é coerente com a inexistência de uma política oficial para o setor e com o fato de que no início desse período, os loucos eram mais tolerados no seio da comunidade e família, uma vez que o processo de urbanização apenas se iniciava. É significativo também, que somente após mais de três décadas da criação do primeiro asilo no Rio de Janeiro em 1852, venha a ser criado o Asilo de Alienados São Vicente de Paulo. Enquanto o Hospício de Pedro II era exigência da capital do Império que crescia rapidamente, o Estado do Ceará localizava-se em uma região pobre e sem maior expressão econômica para o País.

Mantendo o Quadro I como referência e relacionando-0 ao segundo período da assistência psiquiátrica no Brasil (1889 a 1966), constata-se a criação de três hospitais psiquiátricos no Ceará, sendo um privado, um filantrópico e um público. O surgimento das 
referidas instituições e a tipologia variada a que pertencem guardam uma certa lógica com o atendimento da sociedade cearense de então, e com aspectos da política de saúde existente. $\mathrm{Na}$ terceira década do século $\mathrm{XX}$, o Ceará já conta com a capital mais densamente povoada e, portanto, com uma demanda maior por leitos psiquiátricos, o que justifica a criação de uma instituição psiquiátrica privada em 1935, para atender a demanda de trabalhadores organizados nos Institutos de Aposentadorias e Pensões (IAPs). Mas, proporcionalmente, os trabalhadores do IAPs não constituiam maioria dentre a população, havendo, portanto, demanda por um hospital filantrópico, no caso, a instituição criada em 1949.

Neste período também foi inaugurado um hospital público, em 1963. Apesar de começar a funcionar só na década de 60 , esse hospital insere-se na lógica do poder federal iniciada na década de 40 , construindo hospitais psiquiátricos públicos principalmente nas regiőes norte e nordeste do País ${ }^{(5)}$. Como o governo cearense não conseguia arcar com sua parte na construção da instituição, o hospital tem seu funcionamento adiado por quase duas décadas, uma vez que sua planta estava prevista desde $1946^{(6)}$.

No terceiro período da assistência psiquiátrica (1966 a 1974), o Ceará inaugurou sete hospitais. Parece estranho que em apenas oito anos tenham sido criados sete hospitais, enquanto que em quatro séculos foi criado somente um. Como isso se explica? Uma primeira causa, é o fato de que nas décadas de 60 e 70 o Ceará tem proporcionalmente mais população urbana que rural, inversamente ao que ocorria em 1886. É nesse período, inclusive, que são criados dois hospitais em aglomerados urbanos do interior, ou seja, a Instituição VIII na cidade de Sobral (1974) e a Instituição IX na cidade do Crato (1970). A criação do hospital público, Instituição XI, em 1969, por sua vez, está associada à ditadura militar instalada no país desde 1964. Um outro fator, na verdade o mais importante deles, está relacionado à política da Previdência Social, que nesse período firmou convênios com instituições privadas, financiadas por verbas captadas compulsoriamente dos salários dos trabalhadores. Os hospitais psiquiátricos constituíram-se, portanto, em fontes de lucro para os empresários do setor saúde, o que explica a rapidez com que em menos de uma década foram criados a maioria dos hospitais psiquiátricos privados do Estado do Ceará.

$\mathrm{O}$ ritmo de criação de hospitais psiquiátricos privados no Ceará começa a decrescer coincidente- mente em torno de 1974, ano este que marca o início do declínio da psiquiatria enquanto prioridade relativa no setor saúde. É por volta desse ano que se inicia a tentativa do Estado de racionalizar gastos e ampliar a cobertura nos serviços de saúde, via ampliação do número de ambulatórios e desestimulação das internaçðes psiquiátricas prolongadas.

O fato de nos últimos 15 anos (1978-1993) não ter sido criado nenhum hospital psiquiátrico no Ceará e mesmo a desativação de um deles (instituição IV década de 90) está relacionado ao que foi referido no parágrafo anterior. Guarda relação também com o que começou a ser apontado pela VIII Conferência Nacional de Saúde, pregando a municipalização dos serviços de saúde e valorizaçào das instituiçōes públicas, assim como com o movimento pela reforma da assistência psiquiátrica no Brasil que defende a desospitalização progressiva da assistência psiquiátrica, substituindo-a por instituições ambulatoriais, HospitaisDia e outras alternativas de assistência psicossocial. Está relacionado ainda à proibição de aplicação de verbas públicas para a construção de novos hospitais psiquiátricos privados, meta também defendida no ideário da reforma psiquiátrica.

\section{CONSIDERAÇÕES FINAIS}

A assistência psiquiátrica no Estado do Ceará é repleta de contradiçð̃es. Isso é observado na sua história, que começa com a criação de um hospital psiquiátrico, após um período de quase quatrocentos anos após o descobrimento do Brasil. Em um segundo período, surgem as caixas de aposentadorias e pensões e são criados mais três hospitais. No terceiro período são criados sete hospitais - aspecto curioso - mas que pode ser justificado com o fenômeno da urbanização e com um outro fator - a política da previdência social, que firmou convênios com instituições privadas, fontes de lucros para os empresários. $\mathrm{O}$ quarto período marca uma inflexão na tendência de criação de hospitais psiquiátricos privados, fato que começou a ser apontado como meta na VIII Conferência Nacional de Saúde e prosseguiu sendo defendido na I e II Conferências Nacionais de Saúde Mental.

A cronologia de criação dos hospitais psiquiátricos foi traçada e correlacionada com as políticas de saúde do Brasil, mostrando que o processo de criação dos mesmos guarda estreita relação com as políticas de saúde vigentes em cada época. 


\section{REFERÊNCIAS BIBLIOGRÁFICAS}

1. DONNAGELO, M.E.F. Medicina e sociedade. São Paulo: Pioneira, 1975.

2. FÉ, N.M. et al. Interiorização da psiquiatria no Ceará. Revista do Centro de Estudos Melanie Klein, Fortaleza, n.1, p.55$58,1980$.

3. FRAGA, M.N.O. A prática de enfermagem psiquiátrica: subordinação e resistência. São Paulo: Cortez, 1992.

4. PONTE, W. Misericórdia e repressão. In: VELHO, P.M. Organizaçđo da psiquiatria no brasil. São Paulo: Sarvier, 1981.

5. SAMPAIO, J.J.C. Hospital psiquiátrico público no Brasil: A sobrevivência do asilo e outros destinos possíveis. Rio de Janeiro, 1988. Dessertação (Mestrado). Instituto de Medicina Social, Universidade Estadual do Rio de Janeiro.
6. SULIANO FILHO, M.S. Contribuição para história da psiquiatria hospitalar no Ceará. In: SAMPAIO, J.J.C. Hospital psiquiátrico público no Brasil: a sobrevivência do asilo e outros destinos possiveis. Rio de Janeiro, 1988. Dessertação (Mestrado). Instituto de Medicina Social, Universidade Estadual do Rio de Janeiro.

7. TUNDIS, S.A. \& COSTA, N.R. (Org.) Cidadania e Loucura: Política de saúde mental no Brasil. Petrópolis: Vozes/Abrasco, 1987.

8. VAISSMAM, M. Assistência psiquiátrica e previdência social: Análise da política de saúde mental nos anos 70. In TUNDIS, S.A. \& COSTA, M.R. (Org) Cidadania e Loucura: Politica de saúde mental no Brasil. Petrópolis: Vozes/Abrasco, 1987.

Recebido para publicação em 27.2:94 